\title{
ACESSIBILIDADE E INCLUSÃO DE PESSOAS COM DEFICIÊNCIA FÍSICA EM AMBIENTES DE SEXO PAGO
}

\author{
ACCESIBILIDAD E INCLUSIÓN DE PERSONAS CON DISCAPACIDAD EN \\ AMBIENTES DE SEXO PAGO
}

\section{ACCESSIBILITY AND INCLUSION OF PEOPLE WITH PHYSICAL DEFICIENCY IN SEX PAYMENTS}

\author{
Maria Fernanda Sanchez MATURANA ${ }^{1}$ \\ Solange Aparecida de Souza MONTEIRO ${ }^{2}$ \\ Vagner Sérgio CUSTÓDIO ${ }^{3}$
}

RESUMO: Este trabalho teve como objetivo diagnosticar a acessibilidade e inclusão de pessoas com deficiência física em cabarés da cidade de São José do Rio Preto. Teve como hipótese que esses locais apesar de possuírem alvará de funcionamento não possuem adaptações para incluir essas pessoas. O que é um problema muito relevante, pois devido ao preconceito social que envolve as deficiências, em muitos casos o sexo pago é uma importante manifestação sexual. Outra hipótese é que as garotas de programa não querem ou não estão preparadas para atender pessoas com deficiência física, o que gera uma situação de exclusão. Uma terceira hipótese é que os usuários com deficiência utilizam pouco esses serviços devido às dificuldades supracitadas, não usufruindo desta tipologia de lazer. Para chegar aos resultados, aplicou-se uma lista de checagem nos cabarés, aliado a uma entrevista qualitativa com as garotas de programa e outra com homens com deficiência física. Os resultados foram analisados qualitativamente e dispostos em tabelas e gráficos. A pesquisa resultou em 02 listas de checagem, totalizando o número de cabarés legalizados na cidade, além de 17 entrevistas com os deficientes físicos e 10 entrevistas com as garotas. Na primeira etapa, nenhum dos dois estabelecimentos mostrou-se acessível. Já as entrevistas com os homens demonstraram que 03 deles já foram a cabarés, mas todos relataram que esses estabelecimentos não são adaptados, mas que as garotas são receptivas, apesar da falta de informação das mesmas. Dos outros 14 homens que nunca foram a cabarés, $50 \%$ demonstram interesse em ir, mas imaginam não serem locais acessíveis, entretanto, acreditam que serão atendidos por garotas receptivas, mas, além disso, esperam encontrar preconceito por parte dos outros clientes. Já os outros $50 \%$ que não demonstram interesse em ir a cabarés se justificam por possuir medo do preconceito das pessoas, assim como, da falta de acessibilidade, tornando-os inseguros. Destes entrevistados apenas 02 disseram que caso houvesse acessibilidade continuariam a não ir. Das 10 garotas entrevistadas, 06 relataram já ter atendido esses homens, e que foram experiências surpreendentes, mas difíceis, pois não compreendiam as possibilidades sexuais dos mesmos, tornando dificultosa a relação, visto que, não sabiam os limites desses clientes. Das 04 que nunca atenderam, apenas 01 relatou interesse em

\footnotetext{
${ }^{1}$ Universidade Estadual Paulista (UNESP), Araraquara - SP - Brasil. Mestranda em Educação Sexual. ORCID: <http://orcid.org/0000-0002-0844-9908>. E-mail: ma.fersanchez@ hotmail.com

${ }^{2}$ Instituto Federal de Educação Ciência e Tecnologia de São Paulo (IFSP), Araraquara - SP - Brasil. Doutoranda em Educação Escolar. Mestra em Processos de Ensino, Aprendizagem e Inovação. ORCID: <http://orcid.org/0000-0002-1640-0266>. E-mail: solmonteiro@ifsp.edu.br

3 Universidade Estadual Paulista (UNESP), Rosana - SP - Brasil. Professor Doutor. ORCID: $<$ https://orcid.org/0000-0002-1119-7246>. E-mail: vagner@rosana.unesp.br 
atender, entretanto, quando foi perguntado para as outras 03 o principal motivo para a rejeição, relataram principalmente a falta de preparo. Já quando se perguntava se caso fossem capacitadas e informadas a respeito mudariam de opinião, apenas 01 das 03 disse que continuaria não atendendo. Concluiu-se que, o maior problema nesses locais é a acessibilidade física e a falta de capacitação das garotas. Essa pesquisa comprova a importância da acessibilidade nos cabarés como alternativa sexual e de lazer, com isso, pretendeu-se demonstrar a importância das políticas de fiscalização das leis, além de auxiliar os empresários do setor de entretenimento para realizarem ações para incluírem as pessoas com deficiência, considerando a possibilidade de um fomento econômico, e consequentemente as profissionais do sexo, e os potenciais usuários para prestarem e usufruírem desse serviço com uma melhor qualidade.

PALAVRAS-CHAVE: Acessibilidade. Inclusão. Cabarés.

RESUMEN: Este trabajo tuvo el objetivo de diagnosticar la accesibilidad e inclusión de personas con discapacidad física en cabarets de la ciudad de São José do Rio Preto. Tuvo como supuesto que estos lugares, aunque tengan licencia de funcionamiento no tienen adaptaciones para incluir estas personas. Lo que es un problema muy relevante, pues debido al prejuicio social que involucra las discapacidades, en muchos casos el sexo pago es una importante manifestación sexual. Otro supuesto es que las chicas de compañía no quieren o no están preparadas para atender personas con discapacidad física, lo que provoca una situación de exclusión. Un tercero supuesto es que los usuarios con discapacidad utilizan muy poco estos servicios debido a las dificultades mencionadas anteriormente, no utilizando de esta tipología de entretenimiento. Para lograr los resultados, se aplicó una lista de chequeo en los cabarets, aliado a una entrevista cualitativa con las chicas de programa y otra con hombres con discapacidad física. Los resultados fueron analizados cualitativamente y dispuestos en tablas y gráficos. La investigación resultó en 02 listas de chequeo, totalizando un número de prostíbulos legalizados en la ciudad, además de 17 entrevistas con los deficientes físicos y 10 entrevistas con las chicas. En la primera etapa, ninguno de los dos establecimientos se mostró accesible. En las entrevistas con los hombres demostraron que 03 de ellos ya han ido a cabarets, pero todos relatan que estos establecimientos no son adaptados, pero que las chicas son receptivas, a pesar de su falta de información. De los otros 14 hombres que nunca han ido a prostíbulos, $50 \%$ demostraron interese en ir, pero imaginan no ser lugares accesibles, sin embargo, creen que serán atendidos por chicas receptivas, pero, más allá de eso, esperan encontrar prejuicio por parte de otros clientes. Los otros 50\% que no han demostrado interese en ir a cabarets se justifican por tener miedo del prejuicio de las personas, así como de la falta de accesibilidad, volviéndolos inseguros. De estos entrevistados, solo 02 han dicho que si hubiera accesibilidad seguirán no yendo. De las 10 chicas entrevistadas, 06 relataron ya haber atendido a estos hombres, y que fueron experiencias sorprendentes, pero difíciles, pues no comprendían sus posibilidades sexuales, volviendo dificultosa la relación, puesto que, no sabían los límites de estos clientes. De las 04 que nunca han atendido, solo 01 relató interese en atender, sin embargo, cuando se les preguntó a las demás el principal motivo para el rechazo, relataron principalmente la falta de preparo. Ya cuando se preguntó si fueran capacitadas e informadas sobre eso, cambiaron de opinión, solo 01 de las 03 dijo que seguiría no atendiendo. Se ha concluido que, el mayor problema en estos lugares es la accesibilidad física y la falta de capacitación de las chicas. Esta investigación comprueba la importancia de la accesibilidad en los prostíbulos como alternativa sexual y de ocio, además de auxiliar los empresarios del sector de entretenimiento para que realicen acciones para incluir las personas con discapacidad, considerando la posibilidad de un fomento económico, y consecuentemente las profesionales del sexo, y los posibles usuarios para prestar y utilizar este servicio con más calidad. 
PALABRAS CLAVE: Accesibilidad. Inclusión. Prostíbulos.

ABSTRACT: This study aimed to diagnose accessibility and inclusion of people with disabilities in cabarets in São José do Rio Preto. We had hypothesized that these places despite they have business license, they don't have adaptations to include these people. What is a very important problem because of the social prejudice involving deficiencies, in many cases paid sex is an important sexual manifestation. Another hypothesis is that prostitutes are unwilling or unprepared to meet people with physical disabilities which generates a situation of exclusion. A third hypothesis is that users with disabilities use a few of these services due to the above difficulties, not making use of this leisure type. To reach the results, we applied a checklist in the cabarets, combined with a qualitative interview with prostitutes and the other with men with physical disabilities. The results were analyzed qualitatively and arranged in tables and graphs. The search resulted in 02 checklists, bringing the number of cabarets legalized in the city, as well as 17 interviews with disabled people and 10 interviews with the girls. In the first stage, neither establishments proved to be affordable. As for the interviews with men showed that 03 of them have gone to cabarets, but all reported that these establishments are not adapted, but the girls are receptive, despite the lack of information from them. From the other 14 men who have never been to cabarets, 50\% showed interest in going, but imagine they are not accessible locations, however, they believe that they will be served by receptive girls, but also hope to find prejudice on the part of other customers. As for the other 50\% who do not show interest in going to cabarets are justified by having fear of prejudice of people, as well as the lack of accessibility, making them insecure. From these, only 02 respondents said that if there were accessibility they would still not go. From 10 girls interviewed, 06 reported having attended these men, and they were amazing experiences, but difficult because they did not understand the sexual possibilities of the them, making it a troublesome relationship, because they did not know the limits of those customers. From 04 who never attend, only 01 reported interest in attending, however, when asked for the other 03 the main reason for rejection, mainly reported was the lack of preparation. But when asked whether if they were trained and informed about it they would change their opinion, only 01 of 03 said it would continue not answering. It was concluded that the biggest problem in these places is the physical accessibility and the lack of training of girls. This research confirms the importance of accessibility in the cabarets as sexual and leisure alternative, therefore, it was intended to demonstrate the importance of enforcement of the laws policy, and help the entertainment industry entrepreneurs to undertake actions to include people with disabilities considering the possibility of economic development, and therefore commercial sex workers, and potential users to provide and take advantage of this service with better quality.

KEYWORDS: Accessibility. Inclusion. Cabarets.

\section{Enquadramento teórico}

Essa pesquisa pretendeu diagnosticar se São José do Rio Preto possui acessibilidade e inclusão para pessoas com deficiência física em locais próprios para o sexo pago, identificando, desta forma, as necessidades e dificuldades das pessoas com deficiência física em relação à sexualidade e ao lazer, analisando também o comportamento das garotas de programa em relação ao sexo com pessoas com deficiência física.

RIAEE - Revista Ibero-Americana de Estudos em Educação, Araraquara, v. 14, n. esp. 2, p. 1284-1303, jul., 2019. E-ISSN: 1982-5587. 
Nesse contexto, a questão da acessibilidade nos equipamentos de lazer deveria ser realizada no sentido de incluir as pessoas com deficiência nas atividades, como preconiza diversas leis municipais, estaduais e federais.

Muitas vezes pessoas com deficiência tem a sexualidade negada pela coletividade, pois devido ao estigma de serem improdutivos carregam também o estigma de serem assexuados, no sentido de não terem direito ao sexo e mesmo que eles sejam produtivos, continuam estigmatizadas.

Nesse cenário fica difícil para pessoas com deficiência conseguirem parceiros sexuais, e uma das alternativas muitas vezes recorrentes é o sexo pago. O grande problema é que também o sexo pago pode não ser possível para eles, pois os locais não são adaptados e as garotas de programa podem também não serem receptivas.

A cidade de São José do Rio Preto é situada no noroeste paulista, à $443 \mathrm{~km}$ da capital do estado (IBGE, 2010). Cidade escolhida por ser polo receptor de visitantes de cidades vizinhas, principalmente para o lazer, trazendo assim um grande fluxo de pessoas em finais de semanas e feriados.

A exclusão velada por meio de barreiras arquitetônicas e atitudinais das pessoas com deficiência nos estabelecimentos lúdicos, de certa forma aumentam a desvantagem e o desvio social, pois a sexualidade é um aspecto que tornam as pessoas com deficiência participantes da vida social, e, para ser exercida amplamente necessita que direitos fundamentais sejam respeitados como: a intimidade sexual, a dignidade, a liberdade e o lazer, aumentando, a autoestima e a qualidade de vida dessas pessoas.

No entanto, na cidade objeto do estudo, aparentemente a acessibilidade não tem sido respeitada. E essa questão é ainda mais problemática nos equipamentos de lazer para o público adulto como as boates, casa de shows eróticos e cabarés.

Sexualidade é um fenômeno biopsicossocial, e faz parte do crescimento e da personalidade da pessoa. É, a maneira de ser, de compreender e viver o mundo através do nosso ser, como homens ou mulheres e se expressa através da integração, corpo e mente, como elemento básico para a feminilidade ou masculinidade do indivíduo (GLAT, 1989 apud MOURA; CAVALCANTI, 2009). Não são todos os casos que a deficiência impede o ato sexual, seja ela adquirida ou congênita, pois, a deficiência e a sexualidade podem se adaptar uma a outra a partir de orientações (MAIA, 2011).

De acordo com Maia (2010) “As pesquisas [...] sobre sexualidade e deficiências têm divulgado que não é possível afirmar a priori as dificuldades que elas terão ou não no campo sexual" (MAIA, 2010, p. 160). 
Sendo assim, pessoas com deficiência tem o direito de ter uma vida sexual ativa e, nessa perspectiva o sexo não deve ser recriminado, e sim tratado como algo natural. Quando se encaminha da forma certa, a sexualidade ajuda no desenvolvimento afetivo, facilitando a capacidade de se relacionar, portanto, a repressão sexual é algo negativo na vida das pessoas com ou sem deficiência.

O senso comum em relação às pessoas com deficiência é de que elas possuem uma vida sexual pouco ativa ou inexistente em função das suas limitações, mas na realidade o que acontece é a falta de informação e compreensão da sociedade, que nega as manifestações sexuais dessas pessoas.

Desta forma, o modo como às pessoas com deficiência são vistas, influencia na visão que eles têm de si próprias, ou seja, em sua imagem corporal, e isso pode afetar seus comportamentos. Em muitos casos, a deficiência é vista pela coletividade como uma situação de piedade.

Fazendo um levantamento histórico segundo Resource (2005), percebe-se que não é usual oferecer serviços acessíveis para pessoas com deficiência, e quando isso acontece muitas vezes não existe a possibilidade de escolha devido à falta de opção, ou seja, as pessoas com deficiência física ficam limitadas de irem onde querem ir, seja em ambientes de lazer ou em qualquer outro.

Desde outubro de 1999, passou a ser ilegal prestadores de serviços recusaremse a atender alguém por motivos referentes à deficiência, oferecer serviços em condições diferentes ou prestar serviços de pior qualidade. As organizações têm de fazer adaptações satisfatórias para que qualquer um tenha acesso a seus serviços (RESOURCE, 2005, p. 23).

Atualmente, devido à evolução dos meios de comunicação, principalmente a internet que possui muitos sites de relacionamento erótico, e também pelo controle das doenças sexualmente transmissíveis, principalmente a AIDS (Síndrome da imunodeficiência adquirida), para alguns autores como Farley (2009) e Lever (2000), a sociedade está vivendo uma nova revolução sexual, no qual o exibicionismo, o voyeurismo e o comportamento liberal (ménage, swing, sexo grupal) tem sido desestigmatizado, ou seja, devido a maior prevalência desses comportamentos a carga de estigma e preconceito está diminuindo e isso tem incentivado mais pessoas a aderirem a esse tipo de manifestação sexual.

Mais uma vez as pessoas com deficiência não estão inseridas nesse contexto, o que pode gerar uma reflexão de que os conceitos sobre a sexualidade dessa população teve pouca alteração desde a década de 1970, mesmo com todo o discurso inclusivo antidiscriminatório 
que norteia as leis e as relações sociais que estão cada vez mais humanistas em uma sociedade cada vez mais desumana.

O objetivo das entidades protetivas do direito das pessoas com deficiência, bem como as pessoas envolvidas nesse contexto (profissionais, familiares, cônjuges) é o de diminuir as desvantagens e promover a inclusão e acessibilidade.

Nesse contexto, esse trabalho se torna algo relevante por se tratar de 45 milhões de pessoas com deficiência no Brasil (IBGE, 2010). Sendo que devido à situação de acidentes principalmente automobilísticos onde os homens estão mais expostos, aproximadamente $60 \%$ da população com deficiência é masculina o que é um fator negativo para os relacionamentos entre as pessoas com deficiência, pois muitos homens heterossexuais por não encontrarem parceiras com deficiência e serem rejeitados por mulheres sem deficiência recorrem ao sexo pago.

Entretanto, um dos erros do Censo é o de diagnosticar a orientação sexual das pessoas com deficiência, pois a informação referente à orientação sexual vai para um gráfico especifico e a informação sobre a deficiência vai para outro gráfico especifico, não havendo uma correlação dessas duas variáveis, e não fornecendo a informação de quantas pessoas com deficiência são homossexuais ou heterossexuais (IBGE, 2010).

Um dos fatores motivacionais do turismo é o lazer com a possibilidade de ter relações sexuais nos destinos, seja paga ou não. E o turismo sexual, ou seja, aquele cujo principal objetivo são relações sexuais pagas, é um segmento apesar de marginalizado muito importante.

Atualmente, existe também uma preocupação em tornar as atividades turísticas acessíveis para todas as pessoas. Então surge a pergunta: Se o turismo tem de ser acessível, e o turismo sexual é um importante segmento. Porque os cabarés não são acessíveis?

Nessa cena a cidade de São José do Rio Preto por ser um polo de entretenimento da região poderia priorizar a acessibilidade nos serviços inclusive nos cabarés, mas as políticas públicas não priorizam essa situação, isso fica notório no próximo parágrafo.

A Câmara de Rio Preto aprovou o projeto de lei do prefeito Valdomiro Lopes (PSB) que libera estabelecimentos comerciais da realização de todas as obras de acessibilidade. A proposta de Valdomiro beneficia 13 mil estabelecimentos irregulares, que não se adequaram às regras de acessibilidade e estão funcionando sem alvará ou com licença provisória (PAGANELLI, 2009).

Sendo assim, essa pesquisa necessita ser realizada devido à falta de inclusão em ambientes de sexo pago ser um problema muito relevante na vida das pessoas com deficiência, pois, o preconceito e o estigma fazem com que essas pessoas sejam consideradas assexuadas, e o sexo pago em cabarés pode ser uma forma mais segura do que a prostituição de rua, no qual, 
muitas vezes envolve drogas, violência e insegurança. Dessa forma, os cabarés se constituem em uma importante alternativa de liberação da libido, desde que esses locais estejam prontos para recebê-los.

Além de que, a acessibilidade desses locais proporcionará o lazer, visto que, as atividades sexuais podem ser facilitadas em ambientes de sexo pago que atrelam às mulheres com outras formas de entretenimento, como a música, a dança, o contato social, dentre outros fatores. Outro fator positivo seria o fomento econômico da cidade, pois, por ser uma cidade de grande importância na região, recebe muitos visitantes, principalmente para atividades de lazer em finais de semanas e feriados. Desta forma, se os cabarés forem acessíveis, o público com deficiência física poderá agregar recursos ao município, considerando a grande quantidade dessa população.

Com a perspectiva da acessibilidade e da inclusão, as pessoas com deficiência física teriam uma maior satisfação com seus desejos sexuais, e suas relações afetivas, além do avanço na capacidade em lidar com sua própria sexualidade, como afirma Ribeiro (2004), quando mostra que esses fatores são perceptíveis nessas pessoas mesmo sendo negados.

Segundo o autor, é necessário compreender esses desejos e necessidades em que vivem essas pessoas, saber como gostariam de ser tratados diante aspectos de suas vidas afetivosexuais para que o processo se desenvolva. Isso torna claro a necessidade de diagnosticar os problemas enfrentados por homens com deficiência física a irem a cabarés.

Ao considerar o estigma da sexualidade das pessoas com deficiência física, relata-se que os estudos e pesquisas podem ser importantes no processo de uma reformulação mental, questionando os valores e padrões vigentes perante essas pessoas, pois, ao estagnar a evolução teórica, os tratamentos desiguais e preconceituosos irão persistir, assim como, a violência e a repressão sexual.

A ciência provou a inexistência da relação negativa entre sexualidade e deficiência. Desta forma, as pesquisas devem contribuir para a garantia do exercício da vida social dessas pessoas, no qual, possuem direito e sentem necessidade do lazer e principalmente do sexo. Desta forma, devem estar pautadas em reflexões teóricas, científicas e práticas.

Percebe-se que, que tanto as prostitutas como as pessoas com deficiência física sofrem de preconceitos e injustiças, tanto as prostitutas como as pessoas com alguma deficiência. Entretanto, a relação entre as pessoas com deficiência e a prostituição engloba um duplo tabu, desta forma, as discussões a respeito são quase inexistentes, mas quando possíveis, podem tornar a desinformação menor, tornando a visão social mais construtiva a respeito das possibilidades e das necessidades sexuais dessas pessoas. 
Neste contexto, com a inserção de homens com deficiência física nos cabarés, os estigmas supracitados poderiam diminuir, tanto pela falta da valorização das prostitutas que poderão ter um papel fundamental na concepção e autoconfirmação da capacidade desses homens, assim como pela capacidade do homem poder se relacionar com uma mulher tanto sexualmente como socialmente. Além de que, esta relação poderá contribuir para a concepção de que os deficientes físicos são sexuados como qualquer outra pessoa.

Proporcionada essa inclusão, as pessoas com deficiência podem ter uma maior facilidade em se relacionar sexualmente e isso trará consequentemente uma maior independência e autonomia, garantindo a dignidade sexual, a intimidade sexual e o sigilo para frequência em cabarés.

Mediante toda essa discussão, esse estudo se iniciou a partir de um aprofundamento bibliográfico embasado em autores referência do turismo e do lazer como Dumazedier (1975) e Camargo (1986), e também do âmbito do estigma sexual e da acessibilidade, como Glat (1989; 2004), Goffman (1988), Foucault (1990), Colle (1988) e Sassaki (1999).

Em seguida, aplicou-se uma lista de checagem sobre acessibilidade nos cabarés, além de uma entrevista qualitativa semiestruturada com garotas de programa que trabalham nos cabarés, e por fim outra entrevista semiestruturada com homens com deficiência física que aceitaram dar informações sobre a sua sexualidade e a possibilidade ou uso de sexo pago.

Caso as hipóteses sejam comprovadas, essa pesquisa poderá contribuir tanto para o setor público com a fiscalização mais incisiva das leis de acessibilidade, quanto para os profissionais do sexo, que poderão criar estratégias especificas para atender pessoas com deficiência, derrubando dessa forma, as barreiras atitudinais que envolvem a sexualidade dessa população. Além dos empresários que podem se tornar motivados a criarem ou melhorarem estruturas adaptadas, visto que, essa população poderá gerar lucros aos empreendimentos e ao turismo local em si. No entanto, as considerações mais esperadas será a inserção desse público em ambientes de lazer, no qual, poderão atrelar suas necessidades sexuais ao entretenimento, tanto as pessoas com deficiência física residente, assim como os visitantes, que são constantes na cidade.

\section{Método}

\section{Participantes}

Foram participantes desse estudo os seguintes sujeitos: 
Responsáveis pelos estabelecimentos de sexo pago;

Responsáveis pelas associações de reabilitação;

Pessoas do sexo masculino com deficiência física que se autodeclararam usuários de sexo pago na cidade de São José do Rio Preto;

Pessoas do sexo masculino com deficiência física que se autodeclararam não usuários de sexo pago na cidade de São José do Rio Preto;

Pessoas do sexo feminino profissionais do sexo que trabalham em cabarés de São José do Rio Preto;

Os sujeitos participantes possuíam idade mínima de 18 anos, sendo voluntários não pagos e tiveram a possibilidade de assinar a declaração de consentimento esclarecido para participar da pesquisa conforme as normas vigentes para execução de estudos com seres humanos no Brasil.

Todas as informações foram utilizadas somente com fins de pesquisas, e será preservada com todo rigor a identidade dos participantes. A coleta de dados foi realizada em períodos específicos como feriados e finais de semana, no qual os estudos acadêmicos da pesquisadora não foram prejudicados, além de que, esses períodos eram propícios para constar grande quantidade de pessoas na cidade, considerando que, a pesquisa se destinou a pessoas que frequentam a cidade de São José do Rio Preto e não apenas aos moradores da cidade.

\section{Ambientes de estudo}

Ambiente de estudo A: As atividades de pesquisa foram realizadas em cabarés legalizados de São José do Rio Preto previamente selecionados, tendo como base de informações o website: www.gpguia.net. Esses locais foram para a aplicação da lista de checagem (barreira física) assim como para a realização das entrevistas com as garotas (barreira atitudinal).

Os responsáveis tiveram a possibilidade de assinar o termo de compromisso livre e esclarecido com os objetivos da pesquisa explanados. A tentativa inicial foi de realizar a coleta de dados no período diurno quando os cabarés estavam fechados para o público, e a razão social do estabelecimento foi preservada.

Ambiente de estudo B: A outra etapa do estudo direcionou-se para visitas em associações de reabilitação reconhecidas do município para contatar os homens com deficiência física, e esta etapa foi realizada de forma agendada, elencaram-se duas dentre as principais associações a partir da internet e pelo renome das mesmas na cidade. 


\section{Procedimentos Iniciais etapa 1}

Para investigar a acessibilidade nos cabarés participantes do estudo, a primeira etapa foi a aplicação de uma lista de checagem em cada um dos dois cabarés legalizados, visto que, no site gpguia.net foram elencados 10 cabarés, mas apenas 2 são legalizados e estão em funcionamento. A lista de checagem foi baseada na cartilha publicada pelo ministério do Turismo intitulada: Turismo Acessível: volume 02 (BRASIL, 2009). Esse instrumento foi adaptado aos objetivos da pesquisa sendo que foram selecionadas somente informações relevantes, visto que, inicialmente a cartilha continha instrumentos que englobavam não apenas a deficiência física. Desta forma, excluiu-se 2/3 da mesma, os itens referentes às deficiências mentais e sensoriais. A lista de checagem foi demonstrada aos responsáveis que a solicitaram. Ela foi impressa e preenchida pela pesquisadora durante as visitas a partir de aspectos visuais, além da medição de aspectos físicos quando necessário. Alguns tópicos iniciais precisaram ser perguntados aos responsáveis para serem preenchidos.

\section{Procedimentos Iniciais etapa 2}

A segunda etapa foi por meio de informações dos responsáveis na visita aos 2 cabarés, no qual foram contatadas as 10 garotas de programa que trabalham nos estabelecimentos, e que aceitaram participar da pesquisa. Essas mulheres foram submetidas a uma breve entrevista que aconteceu pessoalmente nos próprios estabelecimentos durante as visitas.

Essa entrevista constava as seguintes perguntas:

01) Você já atendeu homens com deficiência física?

Se a resposta for sim para questão 01. Como foi a experiência? Quais os pontos positivos? Quais os pontos negativos?

Se a resposta for não para questão 01 .

02) Você tem interesse em atender?

Se a resposta for sim para questão 02. Como você espera que seja? Você está preparada para atender?

Se a resposta for não para questão 02. Porque você não tem interesse? Qual será a sua atitude se um cliente com deficiência lhe procurar? Se você fosse capacitada para atender esse tipo de público, atenderia?

Mediante as respostas a pesquisadora também utilizou outras perguntas abertas pertinentes à pesquisa que serão relatadas no diário de campo. 


\section{Procedimentos Iniciais etapa 3}

Em um terceiro momento aplicou-se uma entrevista com 04 homens com deficiência física participantes das duas associações citadas, essas visitas foram pré-agendadas com os responsáveis das associações via telefone e via internet, no qual o intuito da pesquisa foi demonstrado. As associações escolhidas são localizadas no município, entretanto, englobam homens de diferentes municípios, visto que, São José do Rio Preto é referência em medicina na região. Desta forma, os entrevistados serão moradores e visitantes da cidade. Os entrevistados se voluntariaram a participar do estudo. Essas entrevistas aconteceram nas próprias associações durante as visitas.

Além de que, 13 homens com deficiência física também foram contatadas via internet através de grupos formados na rede social facebook, esses grupos foram selecionados através da ferramenta busca, utilizando-se de palavras chaves como: pessoas com deficiência física, cadeirantes, homens e São José do Rio Preto.

A essas pessoas serão feitas as seguintes perguntas:

01) Você já foi a cabaré com garotas de programa?

Se a resposta for sim para questão 01. Como foi a experiência? Quais os pontos positivos? Quais os pontos negativos?

Se a resposta for não para questão 01 .

02) Você tem interesse em ir?

Se a resposta for sim para questão 02. Como você espera que seja? Quais os pontos positivos? Quais os pontos negativos?

Se a resposta for não para questão 02. Porque você não tem interesse? Se o local fosse acessível e as garotas de programa receptivas você teria interesse em ir?

Os roteiros de entrevista foram alargados posteriormente no decorrer da própria pesquisa a partir das conversas informais.

\section{Forma de análise dos resultados}

As duas etapas de entrevistas foram analisadas de forma qualitativa. Os resultados foram correlacionados com as informações da lista de checagem, chegando-se às discussões, considerações finais do estudo e formas de intervenção para a temática. 
Os resultados da lista de checagem também foram analisados qualitativamente a partir do modelo diagnóstico retirado da mesma cartilha da lista de checagem (Ministério do Turismo), mas, foi adaptada a partir das especificidades do cabaré.

Para verificar se os aspectos físicos estavam dentro das normas, utilizou-se como base além da cartilha, a ABNT NBR 9050:2004. A norma poderá servir de base aos empresários para instalarem ou colocarem na lei suas instalações. Essas normas foram base para a análise da lista de checagem, ou seja, para verificar o que estava dentro ou fora da legislação os aspectos desse documento foram analisados.

\section{Resultados}

\section{Cabarés}

Foram contatados 02 cabarés na cidade de São José do Rio Preto, visto que, apenas esses dentre os 10 são legalizados ou ainda estão em funcionamento. Esses cabarés foram selecionados a partir do site www.gpguia.net, além de pesquisas complementares via internet e de forma informal com moradores antigos no município. A pesquisadora foi até os cabarés e a maioria deles tinham sido fechados, restando apenas dois.

Os 08 cabarés ilegais encontrados são provavelmente resultantes da prostituição de rua evidente na cidade. Casas de prostituição informais são alvos de roubos, drogas, exploração sexual de menores, dentre outros fatores. A alta na prostituição da cidade está sendo divulgada em redes sociais e mídias televisivas, como o Jornal Nacional da Rede Globo de Comunicações. As reportagens demonstram a facilidade em que "cafetões" possuem em se beneficiar a partir da prostituição de mulheres e a relação da atividade constante em bairros residenciais, no qual, crianças estão expostas a vivenciarem a prostituição de perto. Além de famílias que precisam identificar suas casas para que as mesmas não sejam confundidas com cabarés.

Esses cabarés não possuem alvará e estão expostos a falta de higiene e a diversas contaminações. Essas reportagens fizeram com que a fiscalização se tornasse mais efetiva, entretanto, isso aconteceu apenas para o fechamento de cabarés fora da lei, e os que são legalizados não tiveram importância, além de que, essa fiscalização provavelmente será momentânea e, possivelmente após a mídia deixar de discutir esses assuntos, nem mesmo os cabarés ilegais serão fiscalizados. 
Os dois cabarés legalizados encontram-se em locais geograficamente diferentes, visto que, um deles está situado em um bairro nobre e movimentado da cidade, já o outro encontrase em uma marginal bem distante do centro da cidade, este cabaré é visivelmente escondido, além de estar ao redor de motéis. Essa localização favorece os encontros sexuais, visto que, algumas pessoas só vão ao cabaré para contatar seus parceiros, mas o ato sexual em si acontece fora de lá.

A partir do exposto, um dos responsáveis do primeiro cabaré (A) foi contatado por telefone, o mesmo liberou de forma agendada a entrada diurna no estabelecimento para a pesquisa. A pesquisa foi explicitada pessoalmente ao responsável, mas o mesmo não aceitou assinar o termo de compromisso, entretanto concedeu verbalmente a realização da mesma. No momento da pesquisa, o local estava fechado para clientes, desta forma, a lista de checagem pôde ser realizada sem dificuldades, além de que, o responsável respondeu às perguntas da lista que não puderam ser respondidas visualmente. A lista foi exposta ao responsável para que ele pudesse ver o que estava sendo analisado.

Entretanto, por ser um horário diurno as garotas de programa não estavam presentes. Desta forma, a pesquisadora solicitou o repasse de informações a respeito das mesmas, incialmente pediu-se o celular garotas (neste caso as respostas seriam áudio-gravadas e transcritas) e contatos eletrônicos das mesmas, o responsável geral disse que não tinha a permissão para isto. A pesquisadora então, solicitou entrar na boate em período noturno, mas o pedido foi negado, com a justificativa de que o local não recebe clientes mulheres. Desta forma, o cabaré A foi analisado apenas a questão física.

O segundo cabaré (B) não foi localizado por telefone, e nos períodos diurnos o local se encontrava fechado e sem nenhum funcionário. Desta forma, a pesquisadora foi até o local a noite, visto que, este cabaré libera o recebimento de mulheres. Os responsáveis pelo local não se encontravam, desta forma, a lista de checagem foi realizada de forma visual, e as perguntas iniciais que precisariam ser respondidas por eles, não foram preenchidas. Já as garotas estavam no local, e do total de 14 garotas, 10 delas aceitaram responder a entrevista verbalmente, mas nenhuma delas aceitou assinar o termo de consentimento. As respostas foram inseridas momentaneamente ao papel, mas devido ao barulho as mesmas não puderam ser gravadas, desta forma não foram transcritas.

Os dois cabarés visitados de forma técnica, impediam a captura de fotos, visto que, esses locais devem preservar seus clientes, e funcionários. Este fato, comprova ainda mais o estigma desses ambientes, visto que, boates comuns não colocam empecilhos para tal fato. 


\section{Casas de reabilitação}

Ao que se refere às 02 casas de reabilitação, a primeira delas (A), foi contatada pelo site do Hospital a qual pertence. Solicitou-se uma visita técnica para a realização da pesquisa, explicitando o objetivo da mesma. Desta forma, um responsável enviou um e-mail e agendou a visita sem empecilhos. Entretanto, a pesquisadora compareceu até o local no dia agendado e o responsável cancelou a visita por outros compromissos, relatando que um e-mail teria sido enviado com o informe do adiamento, mas esse e-mail não foi recebido. O responsável solicitou então que um novo agendamento fosse realizado, mas quando a pesquisadora reenviou o e-mail para marcar a nova data, ele relatou que a agenda do hospital estava lotada até o final do ano. Desta forma, a mesma teria que acontecer apenas em 2016, mas, considerando a data final desta pesquisa, essa opção foi descartada.

A associação (B) foi contatada por telefone, mas o agendamento foi dificultoso, visto que, as visitas técnicas poderiam acontecer apenas às quintas-feiras, para que a assistente social pudesse acompanhar a pesquisa. Depois de algumas tentativas, uma data foi concedida pelas duas partes, e a visita pôde acontecer. No local apenas 04 homens foram entrevistados, visto que, a maioria dos pacientes do local possuíam também deficiência mental ou eram menores de 18 anos. Esses entrevistados não se sentiram à vontade para serem áudio-gravados e também não assinaram o termo de compromisso. Com isto, as entrevistas foram apenas repassadas ao papel, no momento em que iam sendo respondidas. Outros homens foram contatados pelos grupos da rede social facebook.

\section{Coleta de resultados lista de checagem}

As listas de checagem foram analisadas de forma visual e se complementou com perguntas feitas aos responsáveis do local, assim como, com as medições realizadas nos instrumentos físicos do cabaré.

O cabaré B foi considerado mais estruturado que o cabaré A porém, ambos não cumprem quase nenhum item proposto pela lei, impossibilitando a autonomia e a segurança das pessoas com deficiência física.

As calçadas encontram-se esburacadas, com desníveis, com perigo de derrapagem tanto de pessoas sem deficiência e principalmente os cadeirantes. Não há sinalização tátil e rampas. Já as guias rebaixadas existem, porém, estão fora das medições adequadas, dificuldade a entrada de um cadeirante ou outra pessoa com deficiência física.

Os ambientes internos foram considerados sem nenhuma acessibilidade, por não possuir 
dispositivos adaptados, além de que, as estruturas são degradadas de forma a prejudicar até mesmo que não possui deficiência física.

\section{Coleta de resultados das garotas de programa}

As 10 garotas de programa entrevistadas foram indicadas por letras para impedir a identificação das mesmas. Dessas 10; 06 relataram já ter atendido pessoas com deficiência física.

As 06 garotas que já fizeram atendimento com deficientes físicos relataram em geral que foram experiências surpreendentes, mas difíceis, pois não compreendiam as possibilidades sexuais dos mesmos, tornando dificultosa a relação, visto que não sabiam os limites desses clientes. Disseram também que não esperavam ser homens sexualmente normais, que possuem ereção e ejaculação, mas algumas relataram que não sabiam como trata-los, a maioria delas os tratam como os outros clientes, pois dizem que recebem pelo serviço como de qualquer outro cliente. Entretanto, uma delas relatou que achou o homem com deficiente físico mais carinhoso e atencioso que os demais. Este fato pode comprovar a concepção da prostituição afetivasexual, e pode mostrar que os cabarés muitas vezes é uma das poucas alternativas para essa satisfação.

Já os pontos negativos se referiram em geral ao público que estava presente no cabaré, que se espantaram com a presença da pessoa com deficiente física, e o outro ponto relatado como constrangedor, seria o fato de elas não saberem como atender essas pessoas, não sabiam como poderiam satisfazer seus desejos sem prejudicar sua deficiência e precisavam questionar seus clientes de como poderiam agir. Entretanto, esse ponto negativo demonstrou que mesmo não sabendo sobre suas dificuldades e possibilidades estariam dispostas a aprender mais sobre, para que pudessem satisfaze-lo mais facilmente.

Das 04 que nunca atenderam homens com deficiência física apenas 01 relatou interesse em atender, a mesma acredita que a experiência deve ser diferente, mas que ela precisa ser mais cautelosa devido a deficiência, e em sua concepção a sexualidade desses homens não são como os demais. Já o questionamento a respeito de sua preparação para o atendimento foi respondida de forma negativa, no qual, relatou não saber o que fazer e como agir com o cliente.

Quando foi perguntado para as outras 03 o principal motivo para a rejeição, relataram principalmente a dificuldade no atendimento, e até mesmo o sentimento de piedade, visto que, nenhuma delas se sente preparada para satisfazer adequadamente esses homens. Perguntou-se também a reação das mesmas com a procura de um cliente com deficiência e, elas disseram que rejeitariam por não estarem preparadas e que justificariam para ele que não saberiam como 
trata-los. Por fim, perguntou-se se caso fossem capacitadas e informadas a respeito mudariam de opinião, apenas 01 das 03 disse que continuaria não atendendo. Essa garota relatou que perderia tempo, visto que, a procura é baixa e que ela não precisa do dinheiro dessas pessoas, pois já possui muitos clientes.

Ou seja, a falta de preparo em geral é o principal empecilho para o não atendimento, considerando que apenas uma não atenderia mesmo se fosse capacitada. Conclui-se que não há, no geral, preconceito por parte delas, no qual, este fato pode ser justificado pelo profissionalismo, ou seja, se estarão pagando elas irão atendê-los normalmente, e se demonstraram dispostas a realizarem seus desejos, como também os afetivos-sexuais.

Considerando ainda uma das hipóteses iniciais de que as garotas de programa não querem ou não estão preparadas para atender pessoas com deficiência física o que isso gera uma situação de exclusão, relata-se que elas não estão preparadas, porém, querem melhorar seus conhecimentos para poderem atendê-los, e que por parte delas a exclusão não acontece, visto que, apenas uma delas não os atenderiam

\section{Coleta de resultados homens com deficiência física}

Dos 17 entrevistados apenas 03 deles relataram já terem ido a um cabaré, comprovando a hipótese da baixa utilização por parte deles pelas dificuldades que esperam encontrar.

Dos entrevistados que se declaram já ter pago por sexo em um cabaré relataram a experiência sendo boa ou ótima, pois tiveram a satisfação sexual que buscaram, pois as garotas se mostraram receptivas e que não os diferenciavam dos outros homens, não demonstrando ter preconceitos, entretanto, relataram que eles precisam instruir as garotas, pois quando deles chegam as mesmas não sabem como agir. Os pontos negativos se direcionam a necessidade de terem que pagar pelo sexo, pois fora dos cabarés disseram que isso seria mais difícil, e que os cabarés não promovem possibilidades posteriores de afeto e de um relacionamento, ou seja, com as prostituas eles irão sanar o problema sexual procurado, entretanto, fora dos cabarés, sabem que o estigma irá prevalecer e que será dificultoso encontrar uma mulher para namorarem ou casarem de fato, no qual poderiam resolver os problemas afetivos-sexuais. Outro ponto bem criticado, foi a acessibilidade física, contribuindo para as dificuldades para a permanência, autonomia e independência dos mesmos nos cabarés.

Dos 14 entrevistados que se declaram não usuários de sexo pago em cabarés, metade possuem interesse em ir, e a outra metade não. Os 50\% que nunca foram a um cabaré, mas que possuem interesse em ir discorreram os pontos positivos e negativos que esperam encontrar. Os 
negativos se relacionam a acessibilidade física, no qual, acreditam que esses locais fazem adaptações "politicamente corretas" apenas para não serem multados, mas que não pensam nas reais dificuldades dos clientes, e que as escadas são sempre um empecilho, além dos banheiros que nunca são acessíveis, pois os empreendedores não enxergam que esse grupo poderia gerar lucros ao local. A falta de acessibilidade também foi relatada como comum na cidade, e o fator de ser um local especifico ao lazer também foi relacionado como um fator negativo a mais, principalmente pela baixa ou inexistência da fiscalização, e por este fator seria difícil irem a esses locais sozinhos e que acompanhados perderiam a intimidade.

Já em relação as garotas de programa, algumas relataram que por estarem recebendo acreditam que serão receptivas. A concepção da incorporação do estigma também foi relatada por eles ao dizerem que eles próprios se sentem inseguros pelas críticas que recebem, e que não se esforçam para contribuir para que esse preconceito seja evitado, pois querer se sentir normal exige-se autoconfirmação deles mesmos. Além de relarem que essa incorporação é consequência do sentimento de pena e preconceito das pessoas por eles, e que isso faz com que eles se excluam e, que saiam apenas com outros deficientes físicos.

Apenas dois entrevistados acreditam que serão locais adaptados, e justificam que os locais privados geralmente são mais acessíveis que os públicos, além de que, por haver poucos cabarés em São José do Rio Preto, os que existem são relatados como provavelmente acessíveis. Além que, por saberem do alvará e por estarem funcionando, acreditam que ao menos os banheiros serão acessíveis, mas que mesmo assim, ir sozinho a esses locais seria algo ainda complicado.

Os entrevistados que se declararam como não sendo usuários de sexo pago e que não possuem interesse em ir a cabarés justificam por não se interessarem a ir ao local, encontramse aspectos religiosos, matrimoniais, médicos, falta de acessibilidade e de afetividade. Ou seja, em alguns casos a religião não permite, em outros o ato de serem comprometidos os impedem, outro acredita que primeiro deve se preocupar com sua saúde física, e outros acreditam que a falta de acessibilidade impediria a permanência de forma autônoma e independente, além da incorporação do estigma demonstrada nas respostas.

Quando foi perguntado se os cabarés fossem acessíveis e as garotas receptivas, um disse que talvez iria caso não estivesse mais comprometido, mas que lá não encontraria questões afetivas, 04 deles relataram que iriam, pois se esses problemas fossem resolvidos essa seria uma boa opção para solucionar esses problemas, as respostas englobaram também a ideia de que a acessibilidade física é um problema maior, além da incorporação do estigma que atrapalha a atividade sexual dos mesmos. 


\section{Conclusões}

Os resultados comprovaram que os cabarés não são acessíveis isso ocorre principalmente por falta de fiscalização pública, que fornece o alvará mesmo o local não sendo acessível. Com o deslocamento, o turismo poderia fomentar os meios de hospedagens, serviços de traslado, alimentação, dentre outros. Mas, infelizmente a os empresários ainda não possuem uma visão ampla sobre a temática e a possibilidade de crescimento economicamente.

Desta forma, essa pesquisa, ao menos poderá instiga-los a modificarem ou criarem ambientes acessíveis com a ideia de maior geração de lucros, considerando que, o estigma comprovado, nunca será eliminado, e a diminuição dele levará um longo processo a ocorrer, tanto o estigma das as pessoas com deficiência física, assim como o estigma de serem prostitutas.

Da mesma forma que é perceptível a dificuldade da diminuição do estigma, também é perceptível a dificuldade na intervenção governamental para aumentar a fiscalização desses cabarés. Com isto, essa pesquisa contribuirá inicialmente na orientação dos empresários que se sentirem instigados a terem um fomento econômico, de como podem adaptar seus estabelecimentos, considerando que se comprovou a ideia de que com acessibilidade, a maioria das pessoas com deficiência procuraria ir em um cabaré.

Essa pesquisa poderá contribuir tanto para o setor público com a fiscalização mais incisiva das leis de acessibilidade, quanto para os profissionais do sexo, que poderão criar estratégias especificas para atender pessoas com deficiência, derrubando dessa forma, as barreiras atitudinais que envolvem a sexualidade dessa população. Além dos empresários que podem se tornar motivados a criarem ou melhorarem estruturas adaptadas, visto que, essa população poderá gerar lucros aos empreendimentos e ao turismo local em si. No entanto, as considerações mais esperadas será a inserção desse público em ambientes de lazer, no qual, poderão atrelar suas necessidades sexuais ao entretenimento, tanto as pessoas com deficiência física residente, assim como os visitantes, que são constantes na cidade.

Outro ponto que poderá ser considerado como extensão da pesquisa é criar formas para que as prostitutas possam se informar mais em como atender esse tipo de cliente visto que, eles demonstraram que elas possuem interesse e que o problema maior não é o estigma e sim a falta de conhecimento. 


\section{REFERÊNCIAS}

BRASIL. Ministério do Turismo. Turismo Acessível: Estudo do Perfil de Turistas - Pessoas com Deficiência. Brasília: Ministério do Turismo. 2009.

CAMARGO, L. O. L. (1986). O que é lazer. São Paulo: Brasiliense. 1986.

COLLE, S. S. Women, sexuality and disabilities. Women and Therapy, vol. 3, n. 2, pp. 247298, 1988.

DUMAZEDIER, J. Questionamento teórico do Lazer. Porto Alegre: PUCRS. 1975.

FARLEY, M. Men who buy sex. Who they buy and what they know. San Francisco, Prostitution Research \& Education. 2007.

FOUCALT. M. História da sexualidade I: a vontade de saber. Rio de Janeiro: Graal. 1990.

GLAT, R. Somos iguais a vocês: Depoimentos de mulheres com deficiência mental. Rio de Janeiro: Editora Agir. 1989.

GLAT, R. Saúde Sexual, Deficiência \& Juventude em Risco. Universidade do Estado do Rio de Janeiro, Faculdade de educação, Núcleo de educação inclusiva. Rio de Janeiro: Banco Mundial Brasil. 2004

GOFFMAN, E. Estigma: notas sobre a manipulação da identidade deteriorada. 4. ed. Rio de Janeiro: Guanabara. 1988.

IBGE. Censo Demográfico 2010. Instituto Brasileiro de Geografia e Estatística. 2010.

LEVER, D. "Clients and call girls: Seeking sex and intimacy." Sex for sale: Prostitution, pornography, and the sex industry. 2000

MAIA, A. C. B. Sexualidade e Inclusão: análise da afetividade e da saúde sexual e reprodutiva em pessoas com deficiência. (Processo 2011/07400-9), Universidade Estadual Paulista. Faculdade de Ciências - Departamento de Psicologia, Bauru, SP. 2011.

MAIA, A. C. B.; RIBEIRO, P. R. M. Desfazendo mitos para minimizar o preconceito sobre a sexualidade de pessoas com deficiências. Revista Brasileira de Educação Especial, Marília, v.16, n.2, pp. 159-176, 2010.

PAGANELLI, J. (2016). Câmara aprova regras mais frouxas para acessibilidade.

Recuperado em: 21 maio, 2016. Disponível em:

http://www.diarioweb.com.br/novoportal/Noticias/Politica/83339,,Camara + aprova + regras + m ais + frouxas + para + acessibilidade.aspx.

RESOURCE, L. The council of museums, archives and libraries. Editora da Universidade de São Paulo, p. 23, 2005.

RIBEIRO, H. Orientação Sexual e Deficiência Mental: estudos acerca da implementação de uma programação, Tese (Doutorado), Universidade Estadual Paulista, São Paulo. 1995. 
SASSAKI, R. Inclusão, construindo uma sociedade para todos. Rio de Janeiro: W.V.A. 1999.

\section{Como referenciar este artigo}

MATURANA, Maria Fernanda Sanchez; MONTEIRO, Solange Aparecida de Souza; CUSTÓDIO, Vagner Sérgio. Acessibilidade e inclusão de pessoas com deficiência física em ambientes de sexo pago. Revista Ibero-Americana de Estudos em Educação, Araraquara, v. 14, n. esp. 2, p. 1284-1303, jul., 2019. E-ISSN: 1982-5587. DOI: 10.21723/riaee.v14iesp.2.12576

Submetido em: 30/09/2018

Revisões requeridas: 20/02/2019

Aprovado em: 30/04/2019

Publicado em: 25/06/2019 